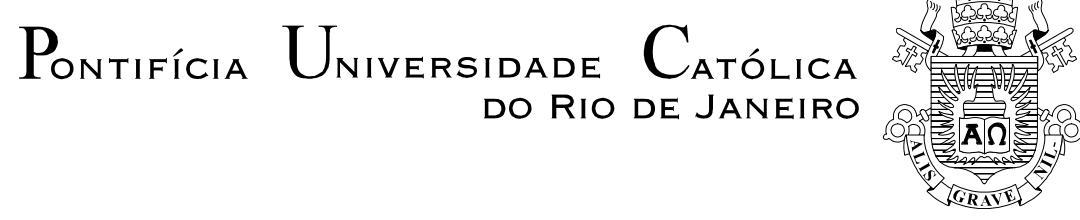

Tiago Leite Costa

Confissões/Ficções de Nelson Rodrigues

Dissertação de Mestrado

Dissertação apresentada como requisito parcial para obtenção do grau de Mestre pelo Programa de Pósgraduação em Comunicação Social do Departamento de Comunicação Social da PUC-Rio.

Orientadora: Profa. Vera Lúcia Follain de Figueiredo

Rio de Janeiro Janeiro de 2007 


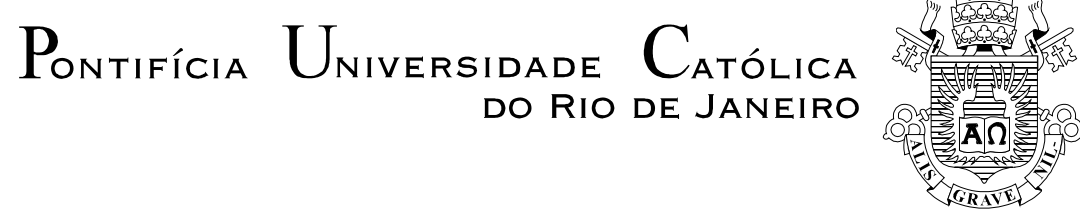

Tiago Leite Costa

\section{Confissões/Ficções de Nelson Rodrigues}

Dissertação apresentada como requisito parcial para obtenção do grau de Mestre pelo Programa de Pósgraduação em Comunicação Social do Departamento de Comunicação Social da PUC-Rio.

Prof. Vera Lúcia Follain de Figueiredo

Orientadora

Departamento de Comunicação Social - PUC-Rio

Prof. Fernando Antonio Resende

Departamento de Comunicação Social - PUC-Rio

Prof. Maria Cristina Franco Ferraz

Departamento de Comunicação Social - UFF-Rio

Prof. João Pontes Nogueira

Vice-Decano de Pós-Graduação do CCS

Rio de Janeiro, 01 de fevereiro de 2007. 
Todos os direitos reservados. É proibida a reprodução total ou parcial do trabalho sem a autorização da universidade, do autor e da orientadora.

\section{Tiago Leite Costa}

Graduou-se em Produção Editorial pela UFRJ em 2003. Publicou o artigo "Idiotas da Objetividade: A crítica de Nelson Rodrigues à nova imprensa" na revista Entre.Meios do departamento de comunicação da PUC- Rio em outubro de 2006. ISSN 1809-0338. (2005)

Ficha Catalográfica

Costa, Tiago Leite

Confissões/ficções de Nelson Rodrigues / Tiago Leite Costa ; orientadora: Vera Foullain de Figueiredo. - 2007.

100 f. ; $30 \mathrm{~cm}$

Dissertação (Mestrado em Comunicação Social)-Pontifícia Universidade Católica do Rio de Janeiro, Rio de Janeiro, 2007.

Inclui bibliografia

1. Comunicação social - Teses. 2. Nelson Rodrigues: Confissões. 3. Crônicas. 4. Década de 1960. 5. Movimento de esquerda. 6. Arte engajada. 7. Modernidade. 8. Pós-modernidade. I. Figueiredo, Vera Foullain de. II. Pontifícia Universidade Católica do Rio de Janeiro. Departamento de Comunicação Social. III. Título.

CDD: 302.23 


\section{Agradecimentos}

À Vera, pela competência e generosidade com que orientou esse trabalho, e principalmente, pela divertida amizade que construímos ao longo desses dois anos;

À minha família e meus “irmãos íntimos”, que eu amo e que me inspiram;

Aos colegas, professores e funcionários da Comunicação da PUC, em especial à Marise (nossa santa protetora), que compartilharam agradáveis momentos de convivência nesse período;

À CAPES, pelo financiamento que possibilitou a realização desse trabalho. 


\section{Resumo}

Costa, Tiago Leite; Figueiredo, Vera Lúcia Follain de. Confissões/Ficções de Nelson Rodrigues. Rio De Janeiro, 2007. 100 p. Dissertação de Mestrado Departamento de Comunica cão Social - Pontifícia Universidade Católica do Rio de Janeiro.

Este trabalho consiste numa análise das "Confissões" de Nelson Rodrigues, crônicas de costumes escritas na passagem da década de 1960 para 1970 e reeditadas recentemente em três coletâneas: $O$ óbvio ululante, A cabra vadia e $O$ reacionário. O propósito da dissertação é, a partir da leitura das crônicas, fazer emergir o personagem/narrador Nelson Rodrigues que trabalha na fronteira da ficção e da confissão. Narrador que cria outros personagens a partir das figuras públicas do Brasil daquele momento. Caberá verificar, então, como Nelson Rodrigues ficcionaliza a si próprio e aos outros protagonistas da década de 1960/70.

\section{Palavras-chave}

Nelson Rodrigues; “Confissões”; Crônicas; década de 1960; Comunicação Social; movimento de esquerda; arte engajada; modernidade; pós-modernidade 


\section{Abstract}

Costa, Tiago Leite; Figueiredo, Vera Lúcia Follain de. Confissões/Ficções de Nelson Rodrigues. Rio De Janeiro, 2007. 100 p. Dissertação de Mestrado Departamento de Comunica cão Social - Pontifícia Universidade Católica do Rio de Janeiro.

This piece of work consists of an analysis of Nelson Rodrigues' "Confessions", custom chronicles written in the passage from the 1960's to the 1970's and recently reedited in three compilations: O óbvio ululante, A cabra vadia, $O$ reacionário. The purpose of this dissertation is to make emerge, from the reading of chronicles, the character/narrator, Nelson Rodrigues, who works on the thin line between fiction and confession. A narrator who creates other characters from the image of Brazilian public figures of the time. It will hence rest to verify how Nelson Rodrigues fictionalizes himself and other protagonists of the 1960's and 70's.

\section{Keywords}

Nelson Rodrigues; “Confessions”; Chronicles; 1960's; modernism; postmodernism. 


\section{Sumário}

$\begin{array}{lr}\text { Introdução } & 9\end{array}$

1. O contexto brasileiro 18

2: Nelson: uma voz dissonante 42

3. As "Confissões" hoje 73

Conclusão 91

Referências bibliográficas $\quad 98$

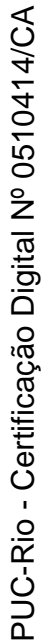


Se aceitamos que existem duas modernidades conflitivas e interdependentes - uma socialmente progressiva, racionalista, competitiva e tecnológica; a outra culturalmente crítica e autocrítica, inclinada a desmitificar os valores básicos da primeira - estaremos melhor preparados para compreender surpreendentes ambivalências e paradoxos da linguagem da modernidade. $\mathrm{O}$ modernismo literário, para tomar um exemplo rápido, é assim ambas as coisas, moderno e antimoderno: moderno por seu compromisso com a inovação, por sua recusa da autoridade da tradição, por seu experimentalismo; antimoderno por sua recusa do dogma do progresso, por sua crítica a racionalidade por sua sensação de que a civilização moderna acarretou a perda de algo valioso, a dissolução de um grande paradigma integrado, a fragmentação do que foi uma poderosa unidade.

Matei Calinescu 